\title{
MAPAS DE ESPESOR DE NIEVE EN LA SIERRA DE GUADARRAMA OBTENIDOS MEDIANTE TÉCNICAS SIG
}

\author{
Andrés Chazarra Bernabé ${ }^{(1)}$, Juan Antonio Fernández-Cañadas López Peláez ${ }^{(2)}$ \\ y Gerardo Sanz Arauz ${ }^{(3)}$
}

(1) Área de Climatología y Aplicaciones Operativas, Agencia Estatal de Meteorología, Leonardo Prieto Castro 8, 28071 Madrid, achazarrab@aemet.es

(2) Delegación Territorial en Madrid, Agencia Estatal de Meteorología, Leonardo Prieto Castro 8, 28071 Madrid, jfernandezcanadasl@aemet.es

(3) Delegación Territorial en Aragón, Agencia Estatal de Meteorología, Leonardo Prieto Castro 8, 28071 Madrid, gsanza@aemet.es

\section{Introducción}

Desde los años 80 del siglo XX, la Agencia Estatal de Meteorología (AEMET) y su predecesor, el Instituto Nacional de Meteorología, elabora boletines nivológicos y de peligro de aludes (BPA) para los principales macizos montañosos situados en el territorio español. En estos boletines se sintetiza la información disponible sobre el estado del manto nivoso y se incluye una predicción sobre la evolución probable de las características del manto y el peligro de ocurrencia de aludes en función del tiempo atmosférico previsto. Esta información resulta fundamental para la planificación y la toma de decisiones en la gestión del riesgo y en la prevención de accidentes y víctimas en montaña relacionadas con la nieve.

Dentro de la información nivológica necesaria para la elaboración de los boletines resulta primordial conocer la extensión de la cubierta de nieve, la cual permite precisar la cota de nieve en las vertientes norte y sur de los macizos montañosos, así como el espesor del manto nivoso en las distintas altitudes y orientaciones del terreno. Esta información tiene, además, interés en otros ámbitos de estudio, como son el análisis y la vigilancia del clima en las zonas de montaña, la estimación de los recursos hídricos

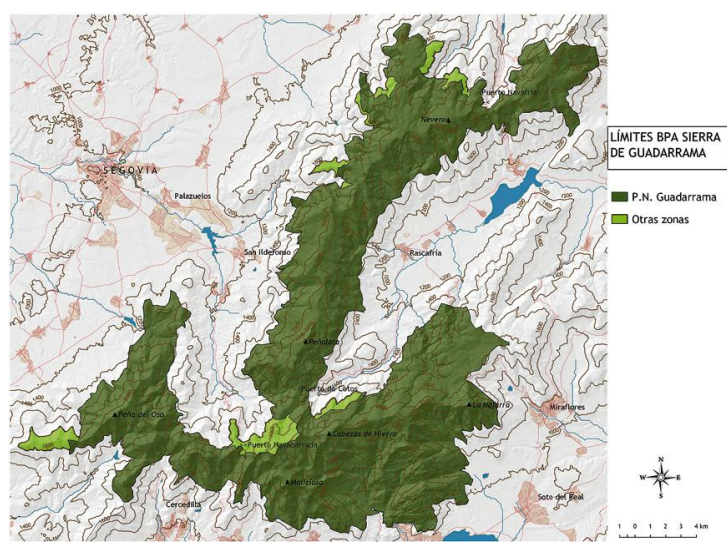
almacenados en forma de nieve o la emisión de avisos por posibles deshielos.

Con el objeto de facilitar esta información a los predictores encargados de la elaboración de los BPA, durante la Campaña de Nieve 2017-2018 de AEMET se han comenzado a generar mapas de espesor de

Fig. 1.- Límites de la zona de estudio. 
nieve en la sierra de Guadarrama obtenidos a partir de datos de espesor tomados in situ y de imágenes de satélite, utilizando técnicas SIG. Se ha escogido la sierra de Guadarrama como área de estudio por tratarse de una zona de extensión limitada de la que se dispone de abundante información nivológica proporcionada principalmente por el personal que participa en la Campaña de Nieve de AEMET de la sierra de Guadarrama.

En el presente trabajo se describe el procedimiento que se está utilizando para la generación de los mapas de espesor de nieve en la sierra de Guadarrama y se muestran los resultados obtenidos hasta el momento (marzo de 2018).

\section{Área de estudio}

El área de estudio coincide con el territorio considerado en los boletines de peligro de aludes de la sierra de Guadarrama que emite la Agencia Estatal de Meteorología, el cual abarca el Parque Nacional de la sierra de Guadarrama en su totalidad más aquellas zonas limítrofes que se encuentran a una altitud superior a $1800 \mathrm{~m}$ (ver figura 1). Se trata de una zona del sistema Central situada entre las provincias de Segovia y Madrid, con una superficie aproximada de $350 \mathrm{~km}^{2}$, en la que son numerosas las cumbres de más de $2000 \mathrm{~m}$ de altitud, siendo el pico Peñalara, con $2428 \mathrm{~m}$, la cima de mayor altitud.

\section{Datos}

Actualmente, los BPA para la sierra de Guadarrama se emiten los jueves a partir de la información recogida los días previos, en los que se realizan diversos sondeos nivológicos en la zona. Con el objeto de que los predictores que elaboran los boletines dispongan cada jueves de información reciente sobre el estado del manto nivoso, se ha elaborado un mapa semanal de espesor de nieve estimada con los datos recogidos preferentemente los miércoles o martes de cada semana. Para la generación de los mapas de espesor se utilizan tanto datos registrados in situ como información procedente de imágenes de satélite.

\section{a) Datos de espesor de nieve}

Los datos empleados proceden de las estaciones meteorológicas de los puertos de Navacerrada y Cotos, pertenecientes a la Agencia Estatal de Meteorología y al Parque Nacional de la sierra de Guadarrama, respectivamente, así como datos de espesor en

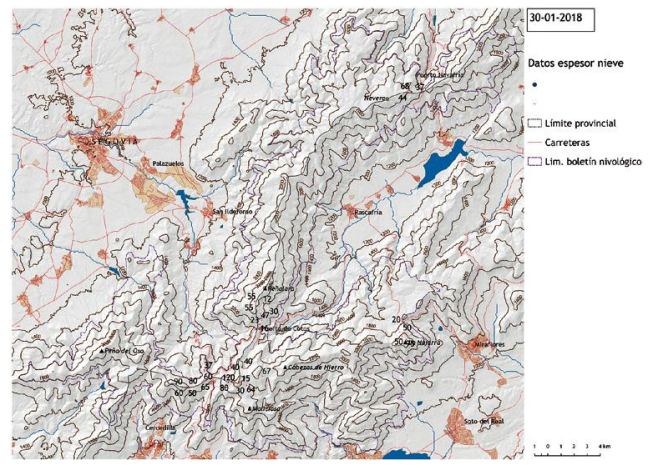
pértigas fijas y en puntos de localización de variable medidos en los sondeos nivológicos que realiza el personal que participa en la Campaña de Nieve de la sierra de Guadarrama. Este equipo está constituido por personal de la Agencia Estatal de Meteorología, agentes forestales de la Comunidad de Madrid, agentes medioambientales de Castilla y

Fig. 2.- Datos de espesor de nieve registrados el 30 de enero de 2018. 
León, vigilantes del Parque Nacional de la sierra de Guadarrama, personal de la Estación de Esquí Nórdico y de Montaña de Navafría, y guías de montaña colaboradores.

El número de datos in situ resulta, por tanto, variable, siendo generalmente mayor la densidad de medidas en las zonas cercanas a los puertos de Navacerrada, Cotos, Navafría y La Morcuera, a los que es posible acceder por carretera. En los mapas generados hasta la fecha el número de datos disponibles ha oscilado entre 15 y 40.

En cuanto a la elección de los lugares para medir el espesor de nieve, dada la alta variabilidad espacial que presenta esta variable se busca que los espesores medidos sean representativos de una amplia superficie alrededor del punto de medida, evitando tanto las zonas de acumulación de nieve (hoyas, tubos, etc.) como aquellas zonas barridas por el viento (crestas, etc.).

\section{a) Datos de satélite}

Además de datos de espesor in situ se utilizan imágenes de satélite, a partir de las cuales es posible estimar la extensión de la cubierta de nieve y asignar valores de espesor cero en puntos en los que las imágenes detectan la no existencia de nieve, aumentando así el número de datos de espesor proporcionados por las medidas in situ.

Fig. 3.- Imagen Sentinel-2 en color natural del 26 de febrero de 2018 en la zona de estudio, en la que puede apreciarse, en color blanco, la cubierta de nieve. Fuente: Agencia Espacial Europea (ESA).

Dado el tamaño limitado de la zona de estudio, se están utilizando con preferencia imágenes Sentinel-2, que tienen una alta resolución espacial. La misión

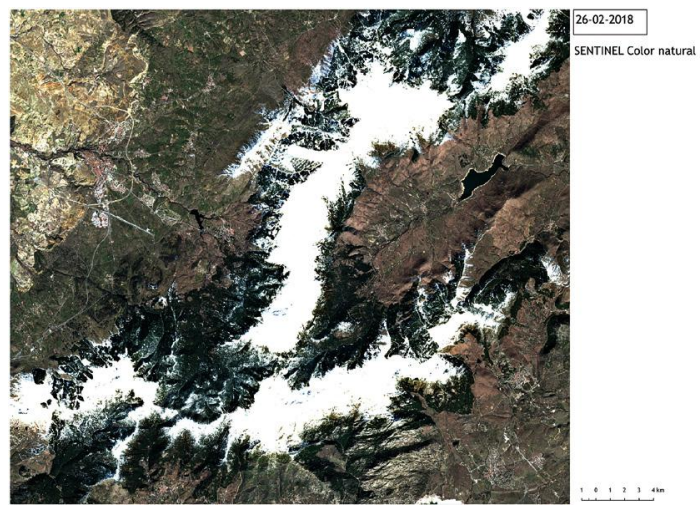
Sentinel-2, perteneciente a la Agencia Espacial Europea (ESA) e integrada dentro del programa Copernicus, consta de dos satélites idénticos en órbita polar separados $180^{\circ}$ entre sí que recogen información en 13 bandas espectrales. La resolución espacial varía dependiendo de la banda entre 10 y $60 \mathrm{~m}$. La resolución temporal para cada uno de los satélites es de 5 días; sin embargo, gracias a la superposición existente entre las órbitas adyacentes, la frecuencia de revisión es mayor en algunas zonas, como ocurre en la sierra de Guadarrama, donde es posible obtener una imagen cada 2 o 3 días.

En los días en los que no hay imagen Sentinel-2 disponible se utilizan imágenes MODIS. Estas imágenes, obtenidas por los satélites Terra y Aqua, pertenecientes a la NASA, recogen información en 36 bandas espectrales. La resolución espacial es menor que la de las imágenes Sentinel-2, variando entre $250 \mathrm{~m}$ y $1000 \mathrm{~m}$ dependiendo de la banda. Sin embargo, la resolución temporal es mayor, siendo posible obtener una imagen diaria de cada uno de los satélites en la zona de estudio. 
No se han utilizado hasta el momento imágenes LANDSAT debido a su baja resolución temporal, de unos ocho días para la zona de estudio.

\section{Metodología}

\section{a) Estimación de la cubierta de nieve mediante el índice NDSI}

El primer paso para la elaboración de los mapas de espesor consiste en la obtención del índice NDSI (Normalized Difference Snow Index) para la fecha de estudio a partir de las imágenes de satélite disponibles en la fecha. El NDSI se basa en que la nieve es muy reflexiva en el espectro visible y muy absorbente en el infrarrojo medio, por lo que utiliza la diferencia normalizada entre dos bandas situadas en dichos rangos del espectro para distinguir las zonas cubiertas por la nieve, en las cuales el índice toma valores relativamente altos. Al ser las nubes generalmente reflexivas en ambas regiones del espectro, el NDSI permite discriminar entre nieve y nubes (Hall et al., 1995).

Las bandas utilizadas para el cálculo del índice son las siguientes:

Sentinel-2: NDSI $=($ B3-B11 $) /($ B3+B11 $)$

MODIS: NDSI $=(\mathbf{B} 4-\mathrm{B} 6) /(\mathbf{B} 4+\mathrm{B} 6)$

A continuación, se aplica la metodología habitualmente utilizada para la determinación de la cubierta de nieve propuesta por Dozier (Cea et al., 2006; Dozier, 1989) la cual selecciona como cubierta nival las celdas en la que el NDSI presenta un valor superior a 0,4. Este procedimiento permite distinguir con bastante precisión las zonas cubiertas por la nieve en terrenos despejados y zonas con arbolado escaso. Sin embargo, presenta importantes limitaciones en las zonas con bosques densos (Hall et al., 1995), láminas de agua, las cuales identifica como superficie nivosa (Cea et al., 2006), y zonas de sombra en la época del invierno en la que el sol se encuentra a una menor altura sobre el horizonte (Dozier et al., 1987).

Las imágenes NDSI obtenidas se utilizan para aumentar la densidad de datos de espesor en la zona de estudio mediante la asignación de valores de espesor cero en zonas no afectadas por las limitaciones anteriormente expuestas, es decir: áreas sin nubes, sin arbolado denso, no coincidentes con masas de agua y que no presenten problemas de

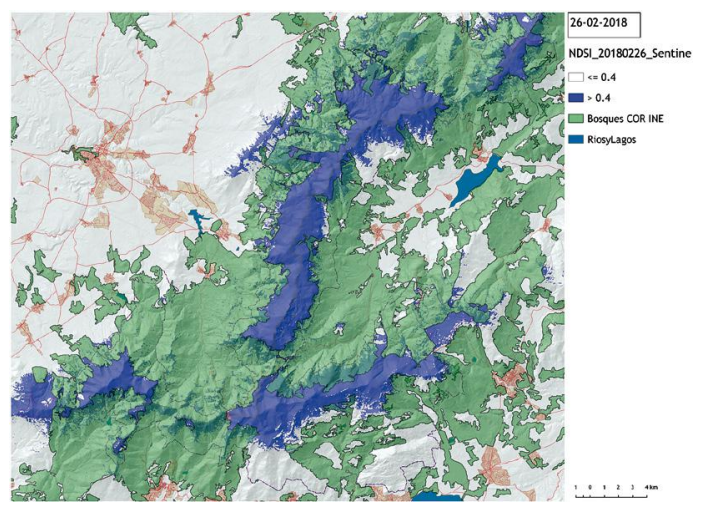
sombras del terreno. Los datos de espesor cero se asignan preferiblemente a puntos coincidentes con el límite inferior en altitud del manto nivoso.

Fig. 4.- Estimación de la cubierta de nieve aplicando el índice NDSI a la imagen Sentinel-2 del 26 de febrero de 2018. Se han superpuesto capas con la extensión de los bosques y las láminas de agua para indicar las zonas en las que el NDSI presenta limitaciones para discriminar la superficie de nieve. 


\section{b) Interpolación espacial de los datos de espesor}

La interpolación espacial de los datos se realiza aplicando un modelo de regresión múltiple paso a paso con diversas variables topográficas derivadas a partir de un modelo digital de elevaciones, sumando a continuación el campo de residuos interpolado mediante krigeado ordinario.

Se utilizó un modelo digital de elevaciones con un tamaño de celda de 20 metros obtenido a partir del MDT05 del Instituto Geográfico Nacional. A partir del modelo digital se obtuvieron las siguientes variables topográficas derivadas: altitud, orientación en las direcciones norte-sur y este-oeste, pendiente, convexidad e índice TPI (Topographic Position Index) para radios de 20, 50, 100 y $200 \mathrm{~m}$. Las orientaciones en las direcciones norte-sur y este-oeste se calculan aplicando el seno y el coseno, respectivamente, a la orientación del terreno (Revuelto et al., 2014).

\section{Resultados}

Desde el inicio de la campaña de nieve 2017-2018 de AEMET han generado mapas de espesor de nieve en la zona de estudio con periodicidad semanal, utilizando los datos recogidos preferentemente los martes o miércoles durante los sondeos nivológicos. El primer mapa se generó la segunda semana de enero de 2018, después de la primera nevada significativa de la temporada y coincidiendo con la emisión del primer boletín de peligro de aludes.

En los casos estudiados hasta la fecha (marzo de 2018), se observa una evidente correlación del espesor de nieve con la altitud en la zona de estudio $(\mathrm{R} \sim 0,8)$, la cual resulta en general más marcada poco después de nevadas intensas, tras las cuales el manto de nieve suele ser más homogéneo. Así mismo, se observa con frecuencia una correlación significativa $(\mathrm{R} \sim 0,5)$ con la orientación del terreno en la dirección norte-sur, la cual suele ser más evidente después de varios días soleados o con escasa nubosidad en los que la fusión es mayor en las laderas orientadas al sur. Del resto de variables, únicamente el índice TPI ha presentado hasta la fecha una correlación significativa en algunos casos, siendo de esperar que a medida que avance la temporada y el manto de nieve pase a ser menos

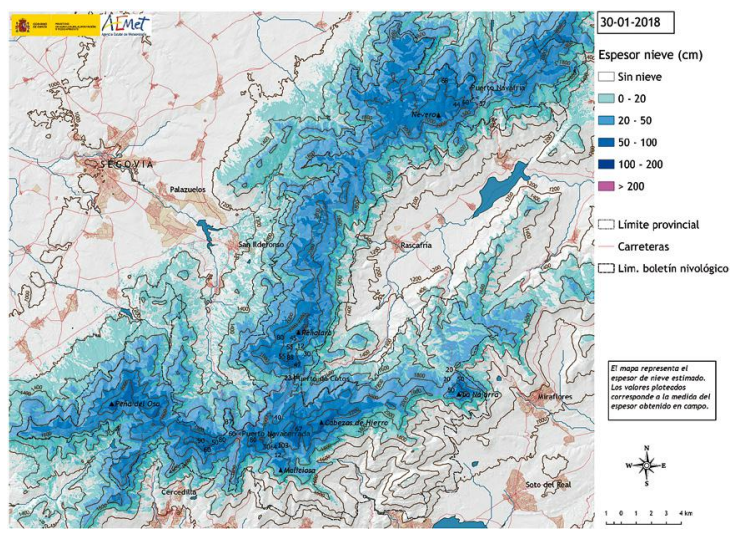
uniforme este índice pueda tomar mayor relevancia.

Fig. 5.- Mapa de espesor de nieve correspondiente al $30 \mathrm{de}$ enero de 2018 obtenido por el procedimiento descrito. 
De la comparación visual entre los mapas de espesores obtenidos y el campo del índice NDSI, se observa en general una evidente similitud en la extensión de la cubierta de la nieve, como puede apreciarse en la figura 6 . Cada semana se selecciona la imagen de satélite más cercana a la fecha de estudio que presente al menos una parte de la superficie del área de estudio libre de nubes. En el caso de que todas las imágenes de fechas cercanas estén cubiertas de nubes, la interpolación espacial se realiza considerando únicamente los datos de espesor in situ.

En cuanto a la validación de los campos de espesor, está pendiente la realización de una validación exhaustiva de los resultados una vez finalice la temporada. Sin embargo, estudios provisionales indican errores medios del orden del 20-30\%. Estos valores, aunque relativamente elevados como cabía esperar, resultan aceptables para una variable que presenta tantas particularidades locales en su distribución espacial como el espesor de la nieve. Se observa además que la incorporación de valores de espesor cero obtenidos a partir de las imágenes de satélite mejoran significativamente los resultados de la interpolación.

\section{Conclusiones}

De los casos analizados hasta la fecha se desprende que el procedimiento descrito proporciona buenos resultados en la zona de estudio, obteniéndose una adecuada representación de la extensión de la cubierta de nieve y una estimación del espesor de nieve de una calidad suficiente para el objetivo perseguido.

La utilización de imágenes de satélite permite aumentar el número de datos de espesor añadiendo valores de espesor cero y, además, sirve para comprobar que la extensión de la cubierta de nieve proporcionada por el campo interpolado se ajusta a la realidad.
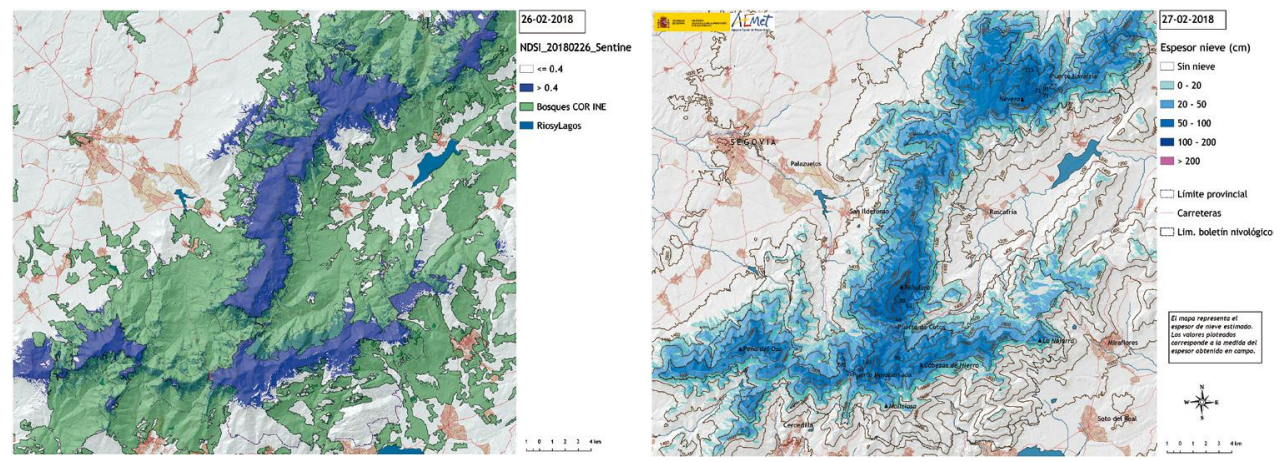

Fig. 6.- Índice NDSI y mapa de espesor de nieve correspondientes al 26 y 27 febrero, respectivamente.

De las variables topográficas analizadas, la altitud y la orientación del terreno en la dirección norte-sur son las que más relacionadas están con el espesor de la nieve, siendo las variables seleccionadas por el modelo de regresión paso a paso en la mayoría de los 
casos. Sin embargo, dado que el periodo analizado hasta el momento es de tan solo dos meses, será necesario esperar a análisis sobre periodos más largos para poder obtener resultados más concluyentes.

No obstante, de los buenos resultados obtenidos en la sierra de Guadarrama hasta el momento cabe esperar que el método descrito pueda adaptarse satisfactoriamente para la generación de mapas de espesor de nieve en otros sistemas montañosos, como los Pirineos o la cordillera Cantábrica, siendo estas tareas pendientes que se espera abordar próximamente en las Campañas de Nieve de AEMET.

\section{Referencias}

- Cea, C., J. Cristóbal J, y X. Pons, 2006: Mejoras en la determinación de la cubierta nival mediante imágenes Landsat y Modis. El acceso a la información espacial y las nuevas tecnologías geográficas, 65-78.

- Dozier, J., and D. Marks, 1987: Snow mapping and classification from Landsat Thematic Mapper data. Annals of Glaciology, 9, 97-103.

- Dozier, J., 1989: Spectral Signature of Alpine Snow Cover from the Landsat Thematic Mapper. Remote Sensing of Environment, 28, 9-22.

- Fernández-Cañadas López-Peláez, J.A, 2014: Los aludes de nieve en el macizo de Peñalara. Nota técnica 14. Agencia Estatal de Meteorología.

- Hall, K., G. A. Riggs, and V.V. Salomonson, 1995: Development of Methods for Mapping Global Snow Cover Using Moderate Resolution Imaging Spectroradiometer (MODIS) Data. Remote Sensing of Environment, 54, 127-140.

- Hall, K., G. A. Riggs, V.V. Salomonson, N.E. DiGirolanno, and K.J. Bayr, 2002. MODIS snow-cover products. Remote Sensing of Environment, 83, 181-194.

- Revuelto, J., J.L. López-Moreno, C. Azorín-Molina, and S.M. Vicente-Serrano, 2014: Topographic control of snowpack distribution in a small catchment in the central Spanish Pyrenees: intra- and inter-annual persistence. The Cryosphere, 8, 1989-2006.

- Sanz, G., S. Alonso, J.A. Fernández-Cañadas, L. Pantoja, P. Sanz, J. Rodríguez, A. Valle, M. Garvía, and A. Chazarra, 2017: Spanish Meteorological Agency Avalanche Warning and Forecasting Activities (poster). 19th Conference of the European Avalanche Warning Services (EAWS), Tutzing (Germany).

- Sanz, G., y R. Pascual, 2017: Predicción meteorológica para zonas de montaña en España. Calendario Meteorológico 2018, 276-288. Agencia Estatal de Meteorología.

- Stoffel, A., N. Foppa, and N. Raderschall, 2006: Mapping Snow Depth in the Alps. Proceedings of the 2006 International Snow Science Workshop, Telluride, Colorado (USA). 